\title{
Toward Public Sector Practice
}

ABSTRACT

In 2016, the University of Hawai ' $i$ at Manoa School of Architecture established the University of Hawai 'i Community Design Center (UHCDC), working in close collaboration with a state legislator to meet the needs of the state government. This unique governmental alignment introduced a novel form of community design that opened up new academic and extramural space for the school and university, taking the form of a top-down public sector practice as distinct from its more common, bottom-up public interest alternative. This paper presents the results of three years of continuous dialogue with the state legislature and over $\$ 2$ million in contracts with state agencies, by reflecting on the transformative effects of public sector practice on design pedagogy. This reflection follows three case study courses: an undergraduate basic design studio; an undergraduate concentration design studio; and an advanced professional practice course, all required within Hawai ' i's undergraduate and graduate curricula. Each case study lists learning, teaching, and long term benefits that flowed from each public sector partnership, focusing on the potential of this model to strengthen and enrich professional education. The evolution of these courses maps the transition from working on projects to working on systems, also a move toward applying equitable academic and design rigor to marginalized project typologies-e.g. utility buildings, infrastructure, renovation, and repair and maintenance. In addition, UHCDC's contract work represents an expanded field of practice, including social science research, service and strategy design, community engagement, information design, engineering, and development studies, demonstrating the broader disciplinary demands of the public sector. More importantly, the significant dividends from this threeyear-old public sector practice identifies an opportunity area for architectural education and practice-design in government.

\section{INTRODUCTION}

Among all of the services that state governments provide-social, cultural, political, economic, and ecological expertise and analysis, for example-design thinking and design services are typically missing. However, there is an emerging trend toward the integration of government and design thinking, facilitated by the demand for solutions to complex and multidimensional urban and regional problems, greater citizen engagement, participatory democracy, innovative leadership practices, and organizational change. This need has shaped a space ripe for design innovation. However, the majority of design innovation providers that have emerged to assist governments have focused largely on systems and services, and not the built environment. A quick study of the public sector innovation field offers insight into the broader realm of public sector practice. This paper reflects on this emerging field of work, the evolution of the University of Hawaii Community Design Center (UHCDC) as a public sector practice, and the impact of this on the teaching of three different required courses in the undergraduate and graduate BEnvD and DArch curricula at the University of Hawai" i.

The difference between public sector practice and public interest

practice (or public interest design) is an important distinction in this

Cathi Ho Schar

University of Hawai'i at Manoa 


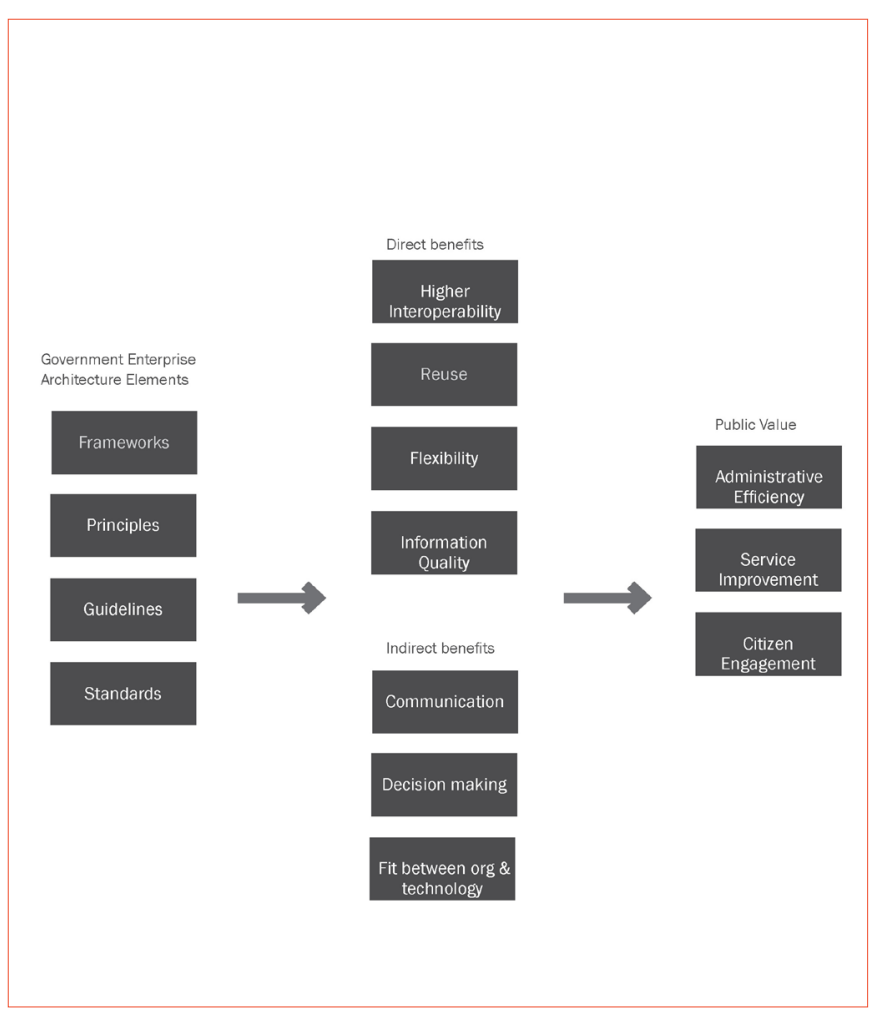

Figure 1. Conceptualizing government architecture (information, enterprise) and its impact M. Janssen, L.S. Flak, and O. Saebo (Reference)

context. Public interest practice (PIP) or public interest design (PID) typically describes a broad circumference of work that at its core, holds the public interest paramount, operating outside of the typical structure of profit and capitol." Described in the Public Interest Design Education Handbook, "this model of practice is innovative in the matter of patronage; projects are sometimes supported by the state or the corporate sector in a compassionate mood (trusts, foundation, and so on), but more usually by nongovernmental organizations, charities, and similar patrons." ${ }^{1}$ As a subcategory of this type of work, public sector practice typically addresses the part of the economy which is controlled by the government-sewers, street lighting, roads, and public education-services available to all. The complexity of delivering these services and the encompassing nature of this "all", provides a space for significant impact for all design disciplines. The disciplines that have oriented to these opportunities include those working in public sector innovation, often providing skill sets across strategy, service design, user research, design thinking, anthropology, and behavioral economics.

\section{BACKGROUND}

A brief history of public sector innovation includes the Danish innovation unit Mindlab, one of the first in-house government innovation labs to integrate user-centered design and training across governmental units. Established in 1999 Mind lab was housed in the Ministry of Industry, Business and Financial Affairs, Ministry of
Employment and Ministry of Education. Other entities include the Helsinki Design Lab, funded by the national innovation fund Sitra in Finland, and the LabX in portugal (run by former heads of Mindlab), all of which mark the growth of these governmental design units across the globe. For-practice companies like IDEO have also developed government focused arms of their company that highlight the magnitude of the opportunities for design in the public sector.

Nearly a decade ago, the Partnership for Public Service and IDEO examined the context for innovation in government, completing focus groups and brainstorms with over 100 people and 45 organizations. They enumerated 20 opportunity areas, and hundreds of solutions. First, they identified a growing need for design innovation. "Expectations of our government are on the rise at a time when budgets and timelines are shrinking, leaving many of our public servants struggling to deliver results." ${ }^{2}$ Ten years later, this need is fully realized. The Observatory for Public Sector Innovation reported in 2019, "The world is in the midst of an unprecedented technological revolution that is transforming economics, governments, and societies in complex and unpredictable ways. This process is fundamentally changing how people live, interact, and work, which invariably affects their relationship with the government and requires a transformation in the design and delivery of public policies and services." ${ }^{3}$

Because of this ongoing technological revolution, the field of government information and enterprise design likewise provides a mature model of public sector practice. Ironically, "government architecture", is the nomenclature used for information and enterprise designers working in government. A diagram of their framework for impact almost exactly describes the framework that UHCDC has learned simply by doing. See Figure 1. UHCDC projects that have an explicit system-wide focus share a common goals structure: to provide frameworks, principles, guidelines, and standards that provide reusable and flexible deliverables aimed at administrative efficiency, better services, and citizen engagement. These projects are typically more complex and collaborative, producing deliverables that engage architectural design as a tool rather than a building.

While most of the design innovation work in the public sector rests just outside of the environmental design disciplines, a handful of design innovation labs offer environmental design services, providing closer precedents to UHCDC. The Design Council is a non-profit organization functioning as an independent government advisor in the U.K.. They work within a framework of places, products, process, and performance. On their website, they list pre-application design assistance, expert design review, and business and development support among their many services. Within the U.S., the City of Boston established the Office of New Urban Mechanics in 2010 as a civic and research development team that manages civic experiments, requests for information, competitions, and prototypes that engage, inform, and empower their constituents. Just last year, long time architecture critic for the Los Angeles Times Christopher Hawthorne joined the City of Los Angeles as the chief design officer, a new role established by the mayor to elevate the design discourse and quality of public architecture and urban design in the city. These emerging in-house built environments-focused design units or positions 
advocate for environmental design as a public good, as fundamental to society as public safety, public health, and public education, and as critical to their success.

\section{UHCDC}

The growth of UHCDC over the last three years recognizes the public university's unique opportunity to provide multi-scale and multi-disciplinary design services to the government in similar ways. The full realization of this developed from a partnership with a state senator who identified a space of mutual benefit between the State and the UHM School of Architecture after enrolling as a graduate student in the school. The senator was the capital improvement project committee chair at that time, responsible for the appropriation of $\$ 3$ billion in capital projects. Based on this experience, he identified the following governmental needs and opportunities for the emerging practice:

- Each year the state legislature appropriates billions of dollars for CIP projects with little or no feasibility work or basis for budget requests. The state needs pre-procurement planning and design services to make better-informed budget decisions.

- As a state/intergovernmental entity, the center is exempt from state procurement requirements, enabling quicker and more nimble contracting.

- As a neutral non-profit party, the university represents a body of experts that can work between agencies and with communities without conflict, or any profit interest in outcomes.

- The government needs visual information to understand future scenarios and make better decisions. Architecture, more than any other built environment discipline, provides the graphic, digital, and physical modelling expertise to provide this legibility.

These points led to the definition of "proof of concept" as the standard scope of work for the state government and the center. This term, borrowed from science, was written into the 2017 state budget as a "scope of work including stakeholder engagement, applied research, conceptual planning, and design investigation, including but not limited to a set of analysis, design schemes, criteria, and initial costs." ${ }^{4}$ The 2017 state budget bill HB100 featured \$1.85 million in seven appropriations to five state agencies, each identified for proofof-concept work. This funding allowed the center to establish partnerships with the State of Hawai' $i$ Office of Planning, Department of Land \& Natural Resources, Department of Public Safety, Department of Accounting and General Services, and the University of Hawai' $i$. These initial partnerships engaged over 10 faculty members in 5 departments, over 200 students in courses, and 40 students in paid internship roles.

The introduction of public sector extramural work also led to an increase in public sector academic work, as professors began to incubate their UHCDC project ideas in their courses. The second half of this paper describes the center's impact on the teaching of three different courses over three years, all taught by the director of the center, the author of this paper, focusing on evolving learning objectives, teaching strategies, student deliverables, and long term dividends. This reflection will also briefly look at UHCDCS extramural or contracted work, more directly shaped by the public sector.

\section{ARCH 201 BEGINNING DESIGN STUDIO}

The ARCH 201 is a second year studio in the BEnvD curriculum that typically extends fundamental design composition and communication skills to the scale of a small building, oftentimes a house. A point of contact at the Honolulu Authority for Rapid Transit (HART), the agency responsible for Oahu's $\$ 20$ billion mass transit line currently under construction, presented an opportunity to collaborate on a project for HART with the College of Engineering. This provided a space to pilot an exchange with engineering students in a senior project course. Timing and teaching assignments resulted in the partnering of ARCH 201 with the CE course, which introduced the pedagogical challenge of developing basic skills in the context of a complex stakeholder and multi-disciplinary context. However, this course (as compared to the other courses discussed in this paper) presented the most unexpected teaching dividends and student learning outcomes because of this overlay.

The project involved the design of a pedestrian bridge, entry building, transit hub, and parking lot connecting to one of the 21 stations along the rail line. These projects were taught as a cumulative series of independent projects, each developed according to its own distinct design methodologies, and guided by HART's interest in more public-serving and culturally-integrative building design. See Figure 2. The new ARCH 201 outcomes, strategies, and dividends that resulted from this public sector partnership, are listed below.

\section{Learning Outcomes}

- $\quad$ understanding a broad range of stakeholder perspectives.

- understanding of a system from part to whole through the lens of transportation.

- understanding relationships between infrastructure and architecture.

- introduction to civil and structural engineering disciplines.

- $\quad$ understanding culture and place-sensitivity as a public value.

- $\quad$ understanding program and circulation as they relate to public experience and community-building.

\section{Teaching strategies}

- The cumulative project format provides lessons greater than the sum of its parts.

- The exquisite corps-like process used to connect each project (requiring each to respond to the one before) provides a soft introduction to urban design thinking.

- The integration of design reviews and stakeholder reviews as separate processes allow students to process 


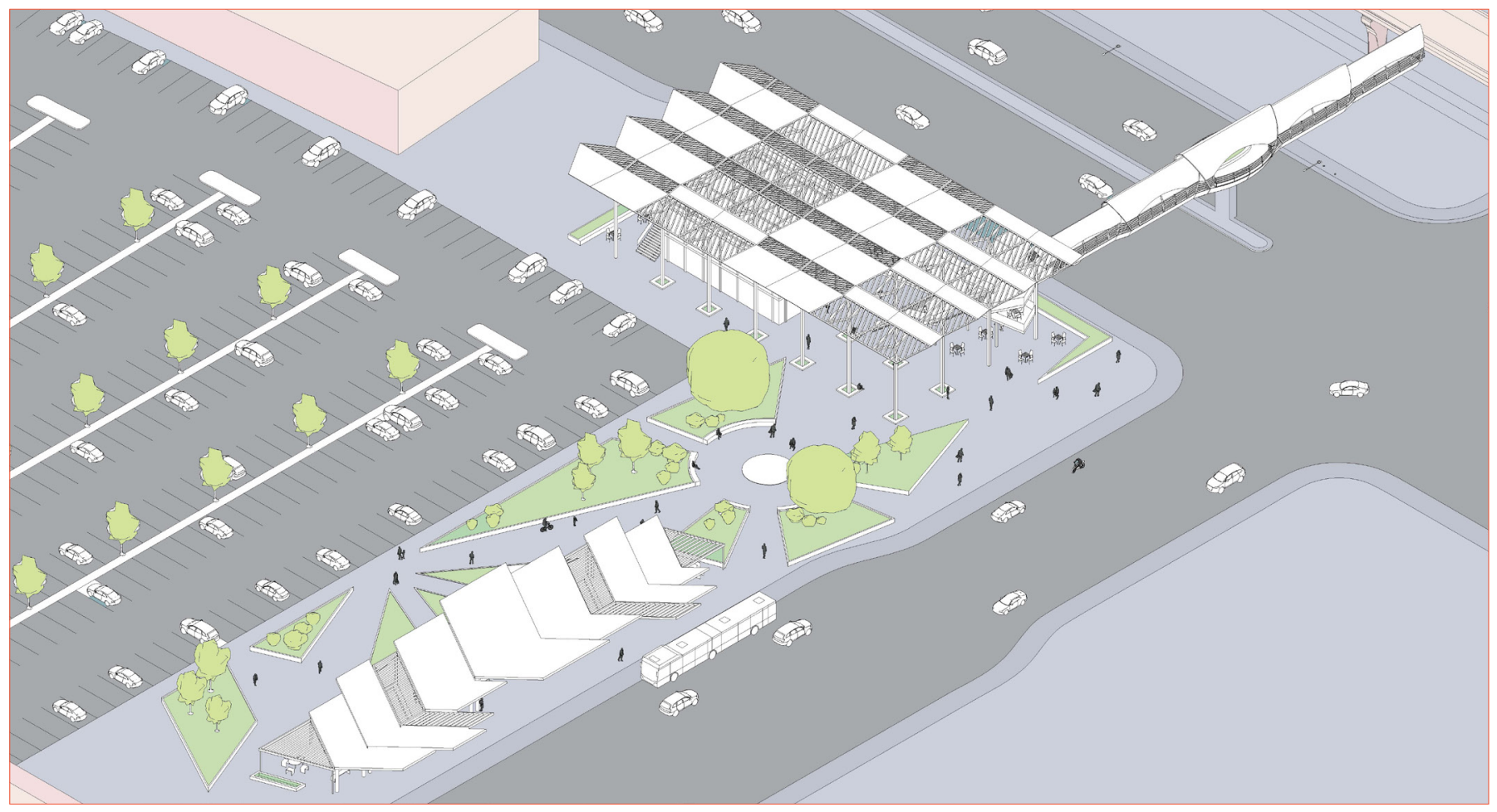

Figure 2. ARCH 201 student work by Kaimana Tuazon. Kualaka'i Station pedestrian bridge, entry building, and transit hub.

different forms of feedback.

- An emphasis on physical models and simple digital drawing techniques (illustrations vs renderings) allowed for greater project development and legibility for stakeholders.

Long term dividends

- Established a working relationship with professor in Engineering.

- Established a working relationship with HART and UH West Oahu.

- $\quad$ ARCH 201 student received an AIA Student Design Award of Excellence.

\section{ARCH 415 CONCENTRATION DESIGN STUDIO}

$\mathrm{ARCH} 415$ is the last studio in the four-year BEnvD program, typically focusing on a larger architectural or urban design project over the course of the semester. Over the last three years, ARCH 415 featured partnerships with the Department of Agriculture, Department of Public Safety, and Department of Environmental Services, which introduced atypical project typologies: a food hub, new prison models, a recycling center, solar farm, and an agri-hood. The nature of these projects, which orient to the challenges of statewide systems and to the public services that they house, likewise changed the pedagogical focus of the course.
- Understanding of statewide challenges and systems interconnectedness.

- Understanding of public agency perspectives.

- Understanding of Hawai'i's unique cultural context for public services. See Figure 3.

- Ability to develop design proposals within the larger context of policy, program, funding, political will, and community support.

- Ability to engage ordinary architecture as opportunity for well executed design.

Teaching Strategies

(Strategies did not differ greatly from other research-based studios).

Long term dividends

- Continued contract work with the Department of Agriculture and Department of Public Safety.

- Two fourth year students received a $\$ 9 \mathrm{~K}$ undergraduate research opportunity grant to continue work on their distributive agriculture project. The studio topics and state partnerships provide solid foundations for grant writing. 


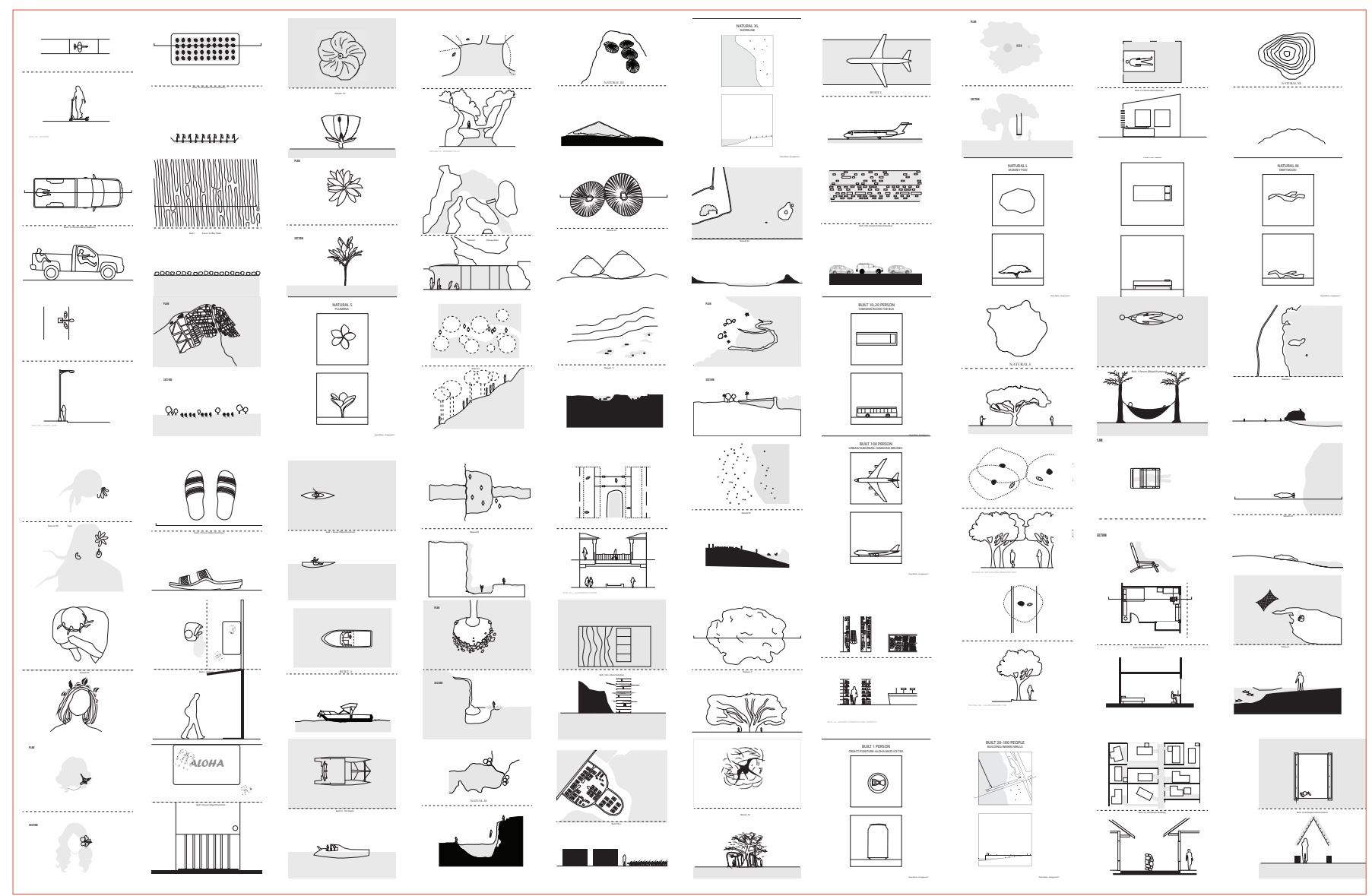

Figure 3. ARCH 415 student work. Hawai'i in plan and section, diagramming a cultural landscape for corrections.

\section{ARCH 745 ADVANCED PROFESSIONAL PRACTICE}

The D.Arch graduate program includes $\mathrm{ARCH} 745$, a three-credit required professional practice course that typically covers the NAAB Realm D requirement surrounding stakeholder roles, project management, business practice, and legal responsibilities. As the center's practice developed, the course likewise evolved to include public interest and public sector practice alongside the more conventional private practice content covered by the textbooks commonly used for this type of course. Each semester, approximately half of the course's time is dedicated to applying the curriculum to a small project presented by a public partner, and the planning of a workshop hosted by the students for the project. These have included projects for the University of Hawai'i at Manoa campus, Hawai' i Public Housing Authority (HPHA), and the City \& County Office of Land Development. Each year, the projects selected by these agencies focused on existing aging projects, repair and maintenance, and underutilized space. This common problem world shared by very different public entities reflects a gaping hole in architectural pedagogy, that mostly ignores existing buildings and the life of buildings beyond construction. Yet a closer look at the CIP budget for the university reveals only a small amount of funding going to new construction, with a majority of funding going to renovation, modernization, repair and maintenance. Engaging this type of public sector work connects students to the realities of maintaining the public built environment, and within an academic setting, allows them to test innovative approaches to otherwise mundane task of upkeeping curbs, sidewalks, crosswalks, trash enclosures, and painted surfaces. See Figure 4.

\section{Learning outcomes}

- Understanding agency responsibilities to the public.

- Understanding the challenges of repair, maintenance, and operation.

- Understanding of the financial context for these issues.

- Ability to generate low tech low cost design solutions to small problems.

- Ability to conceive, plan, and implement a stakeholder or community engagement event.

- Ability to reflect on the success or effectiveness of the event. 
Teaching strategies

- Less teaching leads to more learning-especially in the planning and implementation of the engagement event.

Long term dividends

- $\quad$ Fall $17 \mathrm{ARCH} 745$ course work was shared at a meeting of deans, which earned the attention of the university president who allocated $\$ 500 \mathrm{~K}$ in funding to test implement "light, cheap, quick" ideas across campus.

- 2 fully implemented designs.

- $\quad$ Continued contract work with HPHA and University of Hawai`i.

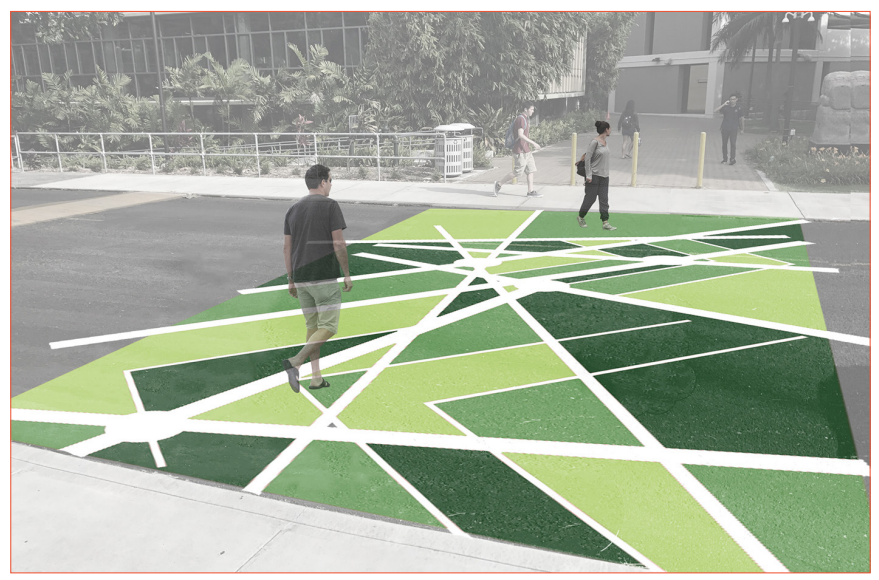

Figure 4. New campus crosswalk design proposed as a "light, cheap, quick" intervention. The crosswalk desgin was implemented in the fall of 2018.

\section{CONTRACT WORK}

Two of the center's larger projects also help to highlight the unique properties of public sector work. First, the center was contracted by the State of Hawai ' $i$ Office of Planning to gather a multi-disciplinary team to implement a proof of concept transit-oriented development (TOD) planning and design study surrounding the Waipahu Pouhala Station. The team included 8 faculty in architecture, planning, and public policy, each providing studies within their areas of expertise. The purpose of the study aims at a deeper understanding of this one TOD area, but also a process that can be repeated at other station sites. The final deliverables for this collective include typical report findings. In addition to the findings, the team developed a process framework and a set of development schemes and costs, design considerations, precedents, block typologies, and an RFP template to assist with future public private partnership developments. Unlike a conventional practice, the work aims at informing decisions and advancing processes rather than the development of a physical design.

A project for the Department of Public Safety included a long period of negotiation to identify the best use of the center's capabilities alongside that of a commercial architecture/engineering practice. This exercise led to a scope that now includes a social science study of recidivism and social enterprise opportunities, waste management opportunities, models for cultural integration, a Cultural Design Resource for the agency, and small proof of concept projects for each facility. This work focuses on alignment, service and capacity building, program development, and pathways for which the built environment plays a supporting role. This context for work pushes the center to collaborate across departments and to work at the intersection of service, spatial, and social design, a new space for architectural pedagogy and practice.

\section{CONCLUSION}

After three years of public sector practice and teaching public sectorfocused courses, the significance and dividends from this specific form of practice have begun to emerge. UHCDC's public sector partnerships prompted the following transitions across teaching and practice: from project to problem, client to stakeholder, single discipline to multi-discipline, systems context to systems applied, design to design considerations, solutions to alternatives, decisions to decision making frameworks, reports to RFP, budgets to proformas, and architectural to infrastructural-understanding architecture as infrastructure in its application across a system.

The architectural discipline has traditionally oriented to change, and more recently to systems, making these developments increasingly more relevant to architectural education and practice. Christian Bason, co-founder of Mindlab, noted in his recent book that "increasingly, innovation labs are structured to recognise that change happens both top-down and bottom-up at the same time, that citizen and staff engagement must happen simultaneously." ${ }^{5}$ This pairing of top-down with bottom-up presents a compelling argument for more community design centers that work with and between both the "top" and "bottom." Taking all this into consideration, the growth of UHCDC provides strong support for the hunch that there is a niche for architecture in the public sector, and an untapped opportunity for architecture programs in public universities to partner with contiguous public agencies.

\section{Notes}

1. Lisa Abendroth and Brian Bell, Public Interest Design Education Guidebook: Curricula Strategies, and SEED Academic Case Studies. (New York: Routledge, 2019), xii

2. "Innovation in Government" IDEO and Partnership for Public Service, January 2011, https://www.ideo.com/ news/innovation-in-government-by-partnership-forpublic-service-ideo

3. Observatory of Public Sector Innovation, Embracing Innovation in Government. Global Trends, February 2019.

4. HB100 Hawai' i State Budget Bill 2017

5. Christian Bason, "Ten years on: Where is public sector innovation headed?" October 11, 2018, https://apolitical. co/solution_article/where-is-public-sector-innovationheaded/ for Apolitical 